\title{
Intramolecular carbonyl-ene reactions in allylsilanes
}

\author{
Asunción Barbero, Francisco J. Pulido, ${ }^{*}$ and $M^{\text {a }}$ Carmen Sañudo \\ Departamento de Química Orgánica, Facultad de Ciencias, Universidad de Valladolid, \\ Valladolid 47011 Spain \\ E-mail:pulido@qo.uva.es
}

Dedicated to Professor Joan Bosch on occasion of his $60^{\text {th }}$ birthday

\begin{abstract}
Silylcupration of allenes has become one of the most efficient procedures for the synthesis of allylsilanes. These substrates are useful building blocks in organic synthesis since they undergo a great variety of highly stereocontrolled silicon-assisted transformations. In particular, the intramolecular carbonyl-ene reaction of oxo-allylsilanes is a powerful strategy for carbocyclic annulation of much potential in synthesis. This article shows a general survey of the recent advances in this field together with the late contributions of our lab to this subject.
\end{abstract}

Keywords: Allylsilanes, allenes, silylcupration, ene reactions, carbonyl-ene reactions

\section{Introduction}

Organosilicon compounds and in particular allylsilane chemistry have attracted considerable attention due to the increasing number of new methodologies that allow useful synthetic transformations. ${ }^{1}$ Over the last decade allenes have emerged as one of the best sources for the synthesis of allylsilanes. ${ }^{2}$ Although unactivated allenes do not easily undergo organometallic addition -failing to react with carbocuprates-, they are readily attacked by silylcuprates giving rise to a great variety of allylsilanes with different substitution patterns. ${ }^{3}$ The stoichiometry of the silylcuprate (higher or lower order) is responsible for the final regioselectivity of the reaction, leading selectively to allylsilanes when a lower order cyanosilylcuprate $\left(\mathrm{R}_{3} \mathrm{SiCuCNLi}\right)$ is used. ${ }^{4}$ Moreover, the high reactivity of the intermediate allylsilane-vinylcuprate species toward electrophiles increases their synthetic potential (scheme 1). ${ }^{2,4}$ 


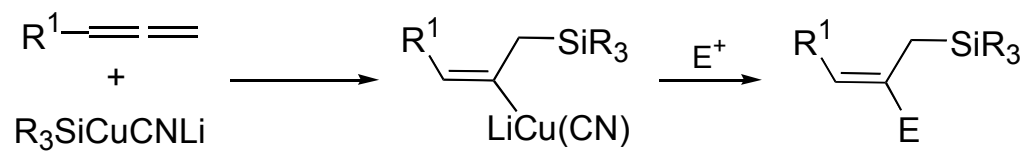

\section{Scheme 1}

Although allylsilanes are known to give ene reactions, ${ }^{5}$ either under thermal or acidcatalyzed conditions, the intramolecular carbonyl-ene reaction of allylsilanes has been much less studied. ${ }^{6}$ Consequently, a considerable lower number of examples have been reported in this area. Nevertheless, from a synthetic point of view, this methodology is highly attractive because it provides efficient strategies for the construction of functionalized ring systems contained in many natural products. In this account, we show a general survey of the recent advances in this area and their significance in synthesis, together with the contribution of our group to this field.

\section{Results and Discussion}

The carbonyl-ene reaction is a powerful tool for carbocyclic annulations and as such it has been extensively reviewed. ${ }^{7}$ Thermal reactions generally need temperatures above $100{ }^{\circ} \mathrm{C}$, however Lewis-acid promoted reactions have been largely exploited due to the mild conditions they require. Mechanistic differences have been found in both methods. Under thermal conditions, the geometry of the early transition state $\mathrm{TS}_{1}$ (scheme 2) is characterized by a boat conformation, where allylic resonance is maximized by tuning the axis of the $\mathrm{C}-\mathrm{H}$ bond of the ene partner parallel to the p-orbital of the neighboring enophile. ${ }^{8}$ On the contrary, Lewis-acid promoted carbonyl-ene reactions proceed with relatively late transition states $\mathrm{TS}_{2}$, through a 6-membered chair-like model, which resemble the products (scheme 2). ${ }^{9}$ The regio- and stereoselectivity of these processes, as well as other stereochemical aspects, can be explained on the basis of the former considerations.
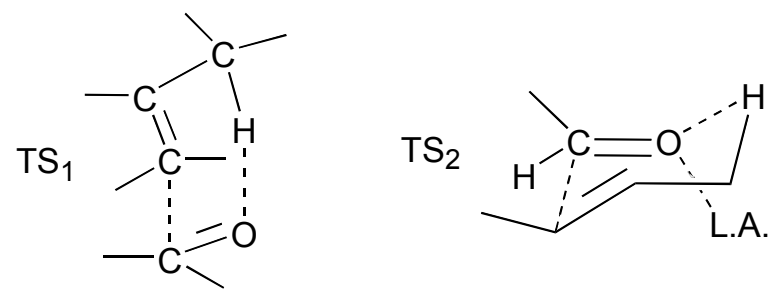

\section{Scheme 2}


On the other hand, the degree of concertedness of the Lewis-acid promoted carbonyl-ene reactions has been the subject of controversial discussions. ${ }^{10}$ They are usually discussed in terms of the continuum from concerted to cationic mechanism. In one end, the reaction proceeds by a concerted mechanism, through a single barrier process. In the other, the reaction can be considered to be stepwise via cationic intermediates. Whatever is the level of concertednees, the hydrogen transfer to carbonyl can be either a fast process or the slow rate-determining step.

When vinyl- or allylsilanes are used as the ene-component in carbonyl-ene reactions, a high regio- and stereocontrol is frequently observed. The ability of silicon to stabilize a developing $\beta$ cationic center is believed to be responsible for the rate and stereocontrol of such reactions. In this sense, the influence of the silyl group in an intramolecular H-ene reaction may be ascribed to the hyperconjugation effect of the $\sigma-\mathrm{C}-\mathrm{Si}$ bond. The silyl group lowers the energy of the transition state and allows the reaction to proceed at a temperature lower than that of the corresponding all-carbon analogue reaction, thereby increasing selectivity and excluding the formation of undesirable by-products. ${ }^{7 \mathrm{a}}$

Intermolecular ene-reactions of allylsilanes offer a valuable method for the formation of $\mathrm{C}-\mathrm{C}$ bonds in natural product synthesis. The resulting vinylsilane adduct may undergo further useful reaction at the silicon atom, thus enlarging its synthetic scope. Thus, Thomas ${ }^{11}$ and coworkers reported recently the synthesis of a sixteen-carbon fragment contained in Bryostatins whose key step features a stereoselective ene reaction between an allylsilane and an alkynone (scheme 3). Coupling was carried out with excellent stereoselectivity by using zinc(II) iodide. Further fluoride promoted deprotection- cyclization leads to the Bryostatin precursor.

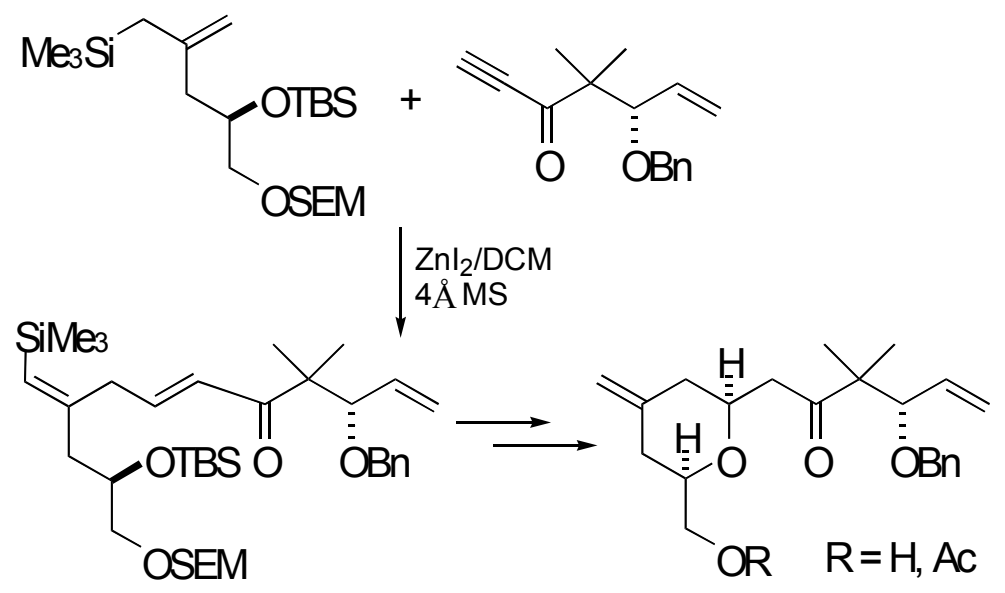

\section{Scheme 3}

Monti $^{5 \mathrm{a}}$ has studied the chemo- and regioselectivity of the Lewis acid-induced reaction of sterically unhindered isocyclic allylsilanes with 3-butyn-2-one. Surprisingly, in all cases the Sakurai reaction is suppressed, but the final outcome depends on the framework of the allylsilane. Cyclopentanic core allylsilanes give mainly [2+2] cycloadition products, whereas cyclohexanic framework allylsilanes afford solely H-ene adducts (scheme 4). 


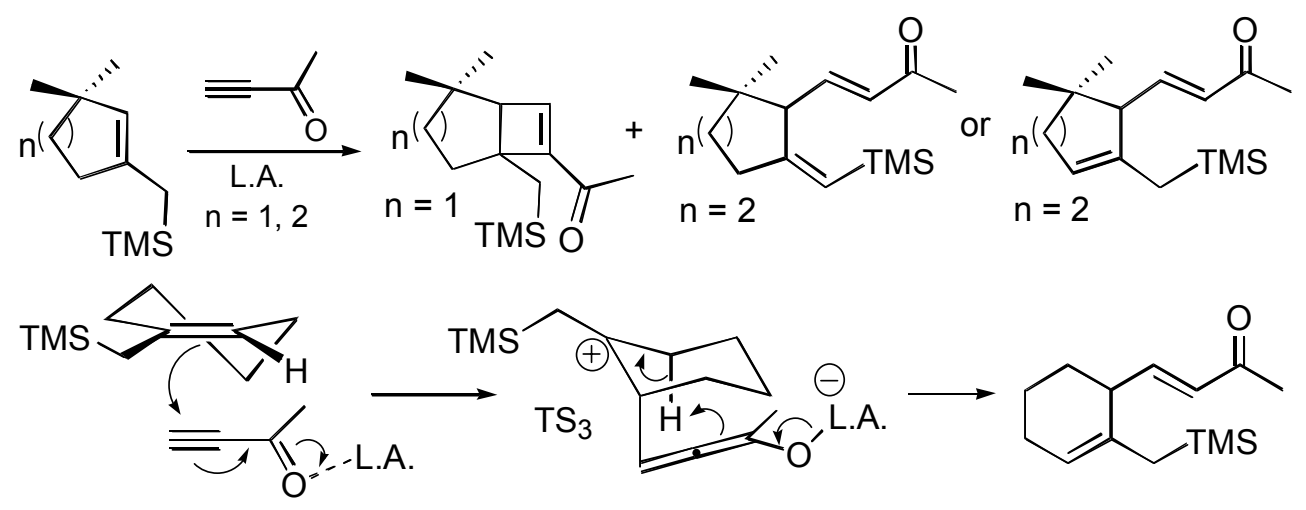

\section{Scheme 4}

The regioselectivity may also depend on the Lewis acid employed. It has been suggested that the regioselectivity of these $\mathrm{H}$-ene reactions can be explained by the geometry of the intermediate zwitterions. Thus, formation of major products are favored by a well positioned endocyclic axial hydrogen, via a chairlike transition sate of the type $\mathrm{TS}_{3}$ (Scheme 4).

The same authors reported the synthesis of $(+)-(2 \mathrm{R}, 6 \mathrm{R})$-trans- $\gamma$-irone (a worthwhile intermediate in the synthesis of many natural terpenes) by an analogue intermolecular ene reaction of allylsilanes and butynones (Scheme 5). ${ }^{5 \mathrm{~b}}$

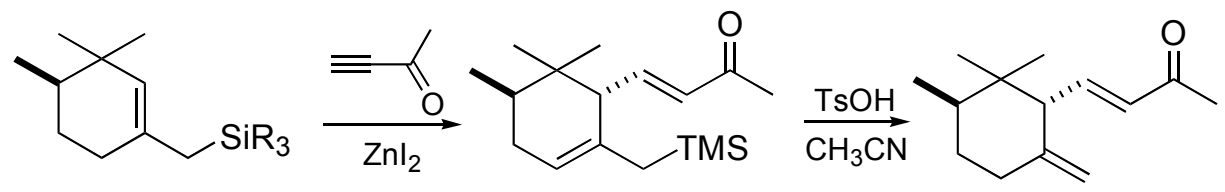

\section{Scheme 5}

Intramolecular ene reactions involving allylsilanes have also been reported. As an example, in an elegant approach, cis- $\gamma$-irone has been stereoselectively synthesized by a thermal ene reaction of the $\beta$-(alkoxy)acrylate depicted in scheme $6 .^{12}$ Cyclization yields an 3oxabicyclo[3.3.1] nonane derivative which is a key intermediate of the cis- $\gamma$-irone (scheme 6). The energetically favored transition state $\mathrm{T}_{Z}$, yielding the major $(Z)$-vinylsilane product, turns the exocyclic $\alpha$-silylated methylene $\mathrm{C}-\mathrm{H}$ bond to be coplanar with the potentially empty carbon $\mathrm{p}$ orbital (scheme 6). Formation of the major product $Z$ instead of the $E$-isomer could be explained by the fact that when rotation occurs, the main transferred hydrogen is the one in close proximity with the negative part of the enophile. 


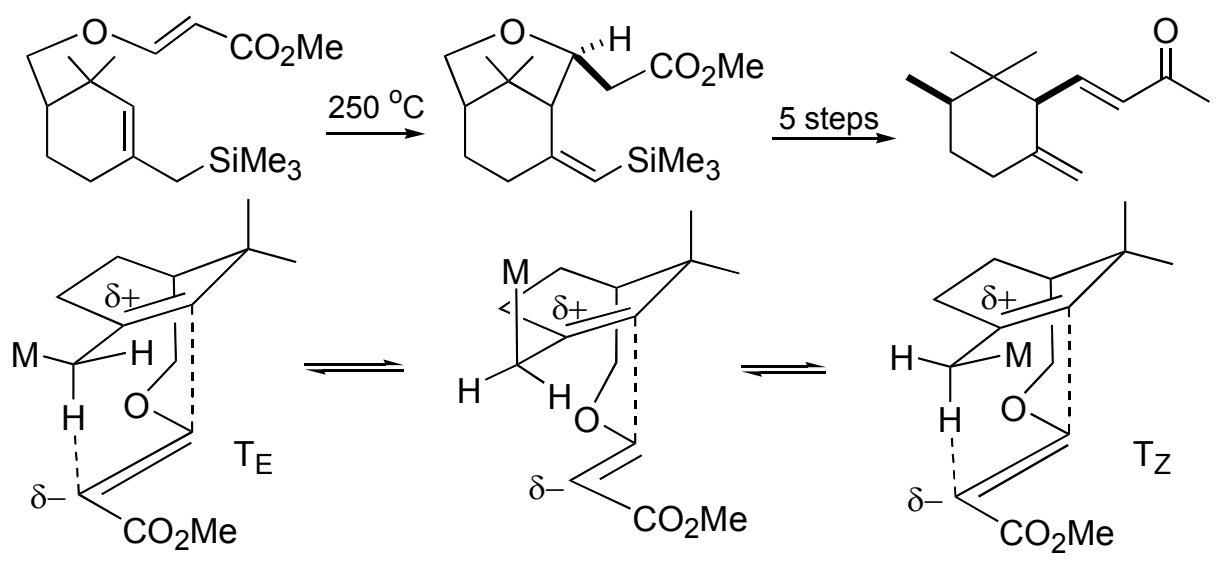

\section{Scheme 6}

The intermolecular carbonyl-ene reaction of substituted allylsilanes with different aldehydes, followed by an oxidative double desilylation, provides an efficient access to a wide range of exo-methylene- $\gamma$-butyrolactones (scheme 7). ${ }^{13}$

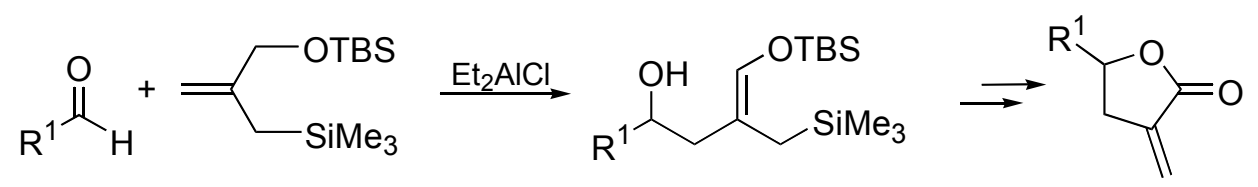

\section{Scheme 7}

In a similar process, Taddei ${ }^{14}$ and coworkers have reported a highly stereoselective synthesis of 1,2-aminoalcohols by $\mathrm{BF}_{3}$ promoted intermolecular carbonyl-ene reaction of allylsilanes and $\alpha$-aminoaldehydes (scheme 8 ). In the reaction conditions used, desilylation occurs spontaneously. The H-ene reaction is the key step in the synthesis of potential HIV-1 Protease Inhibitors.<smiles>[R5]CC(=C)CCCl</smiles>

\section{Scheme 8}

Silicon tethered ene cyclizations have also been investigated. ${ }^{15}$ In particular, the intramolecular carbonyl-ene reaction of vinylsilanes and aldehydes has been recently studied as a convenient route to the synthesis of stereo-defined silacyclohexanols carrying exocyclic methylene groups (scheme 9). The presence of a silicon tether not only would predict high levels of regio- and stereocontrol, but subsequent oxidative removal of the silicon tether would allow 
additional oxygen functionality that has been used by the authors in the synthesis of carbohydrates.<smiles>C=C(C)[Si](C)(C)CC(C)C=O</smiles><smiles>C=C(C)[Si](C)(C)C(C)CC=O</smiles>

\section{Scheme 9}

Our interest in the intramolecular carbonyl-ene reaction of allylsilanes - a very little kown reaction-came as the result of the investigations previously reported on silylcupration of allenes. As it was mentioned at the beginning of this article, ${ }^{4}$ low order cuprates as phenyldimethylsilylcyanocuprate $\mathbf{1}^{16}$ control the regiochemistry of the silylcupration of allene (1,2-propadiene) leading exclusively to allylsilanes (scheme 1). Reaction of the intermediate vinylcuprate 2 with $\alpha, \beta$-unsaturated ketones or aldehydes affords oxo-allylsilanes 3-8, which are valuable intermediates in cyclopentane annulations (scheme 10). ${ }^{2,4}$

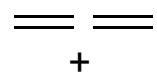

$\mathrm{PhMe}_{2} \mathrm{SiCuCNLi}(\mathbf{1})$
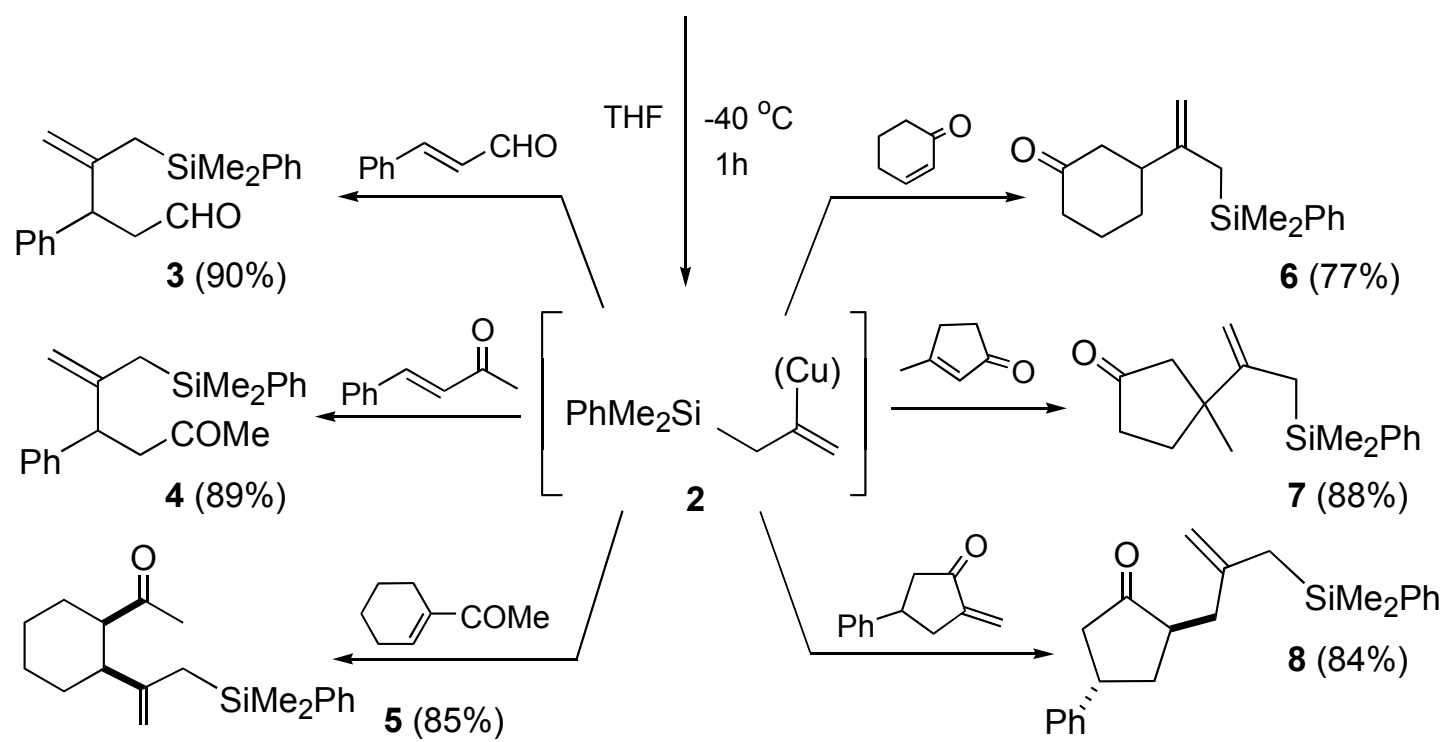

\section{Scheme 10}


Thus, silicon-assisted intramolecular cyclization of the former oxo-allylsilanes, in the presence of a Lewis acid (usually $\mathrm{TiCl}_{4}$ or $\mathrm{EtAlCl}_{2}$ ), results in formation of cyclopentane ring systems with a high degree of stereocontrol. The main feature of the cyclization is the invariable formation of 3-methylene-1-cyclopentanols 9-12, a moiety very common in some terpene families (Scheme 11). ${ }^{4}$

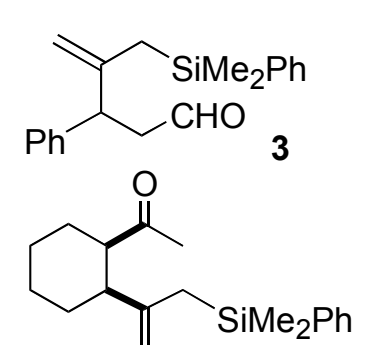

5

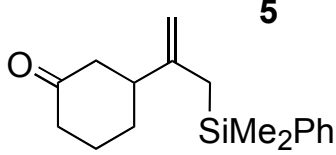

6
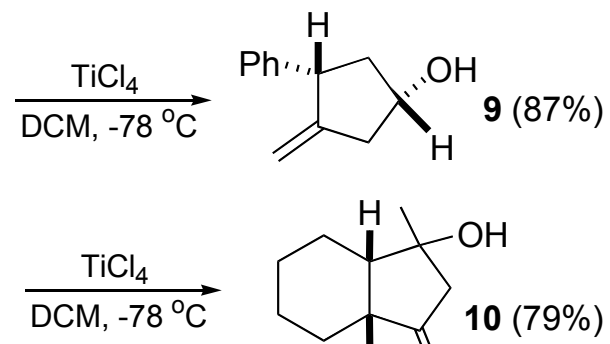<smiles>C=C1CC(O)C2CCCCC12</smiles><smiles>C=C1CC2(O)CCCC1C2</smiles>
$11(92 \%)$<smiles>C=C1C[C@H]2C[C@H](P(c3ccccc3)C(C)C)C[C@]2(O)C1</smiles>

\section{Scheme 11}

From the above results, it is clear that oxo-allylsilanes containing the phenyldimethylsilyl group undergo allylsilane-terminated cyclizations, losing the silicon group and following the classical $S_{E}$ mechanism involving stabilized carbocations species $\beta$ to silicon. Surprisingly, the behavior of oxo-allylsilanes bearing the tert-butyldiphenylsilyl group (prepared as before by using the low order cuprate $\left.t-\mathrm{BuPh}_{2} \mathrm{SiCu}(\mathrm{CN}) \mathrm{Li}^{4}\right)$ is perceptibly different from that observed for the phenyldimethylsilyl group. Thus, the intramolecular acid-catalyzed cyclization of the allylsilane-ketones 13-17 gave cyclopentenols 18-22 which maintain the silyl group, in clear contrast with the behavior shown by the phenyldimethylsilyl analogues where the silyl moiety is always lost (Scheme 12). ${ }^{17}$ These results were consistent with the intervention of an intramolecular carbonyl-ene reaction involving the oxo group and the allylic moiety bearing the hydrogen $\beta$ to carbonyl. Transfer of hydrogen from the allylic position $\alpha$ to silicon was never observed. 


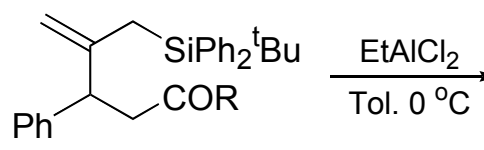

13, $\mathrm{R}=\mathrm{H}$

$14, \mathrm{R}=\mathrm{Me}$

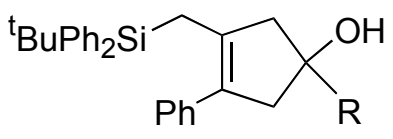

18, $\mathrm{R}=\mathrm{H}(69 \%)$

$19, \mathrm{R}=\mathrm{Me}(77 \%)$
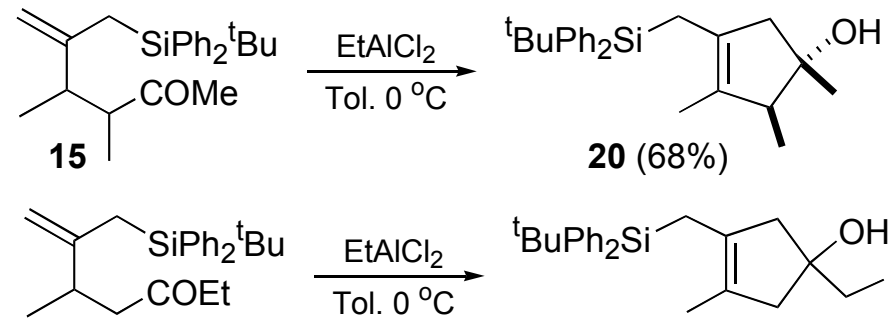

16

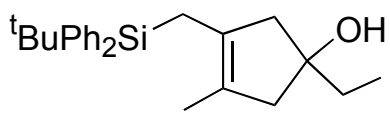

$21(85 \%)$

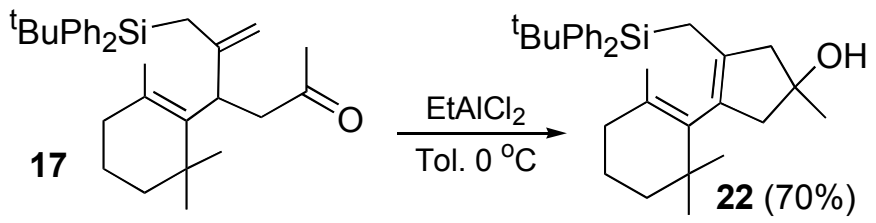

\section{Scheme 12}

To our knowledge, this is the first time that an intramolecular carbonyl-ene reaction of type II involving allylsilanes was reported. Formation of H-ene products depends on the accessibility of the $\mathrm{H}-\beta$ to carbonyl and on the energy of the TS during the ene reaction (scheme 13). From the classical mechanism standpoint, it is generally believed that the concerted ene reaction involves a highly asynchronous transition state featuring a well-developed $\mathrm{C}-\mathrm{C}$ bond prior to a relatively late proton transfer toward the oxygen. ${ }^{18,7 \mathrm{a}}$ This will be favored by the stabilization of the partial positive charge at the carbon atom $\beta$ to silicon (the so-called $\beta$-effect). Although this effect is generally accepted, there are not much experimental evidences that prove it, and theoretical chemists hotly dispute it. In this sense, results depicted in scheme 12 constitute one of the few examples in which solid experimental data are in favor of the $\beta$-effect.

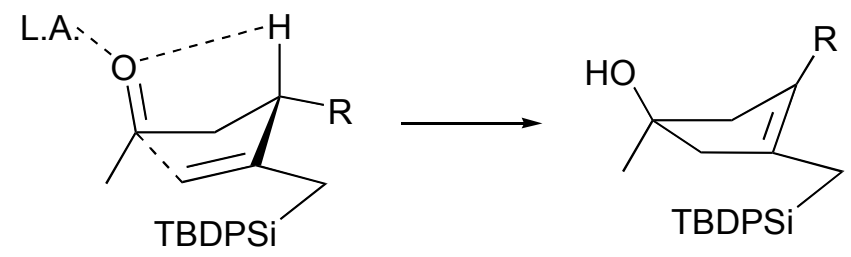

\section{Scheme 13}

As it was expected, in the case of substituted oxo-allylsilanes 23-24, the lack of a hydrogen $\beta$ to carbonyl causes the silyl group to come off leading to the methylenecyclopentanols 25-26 through the usual $\mathrm{S}_{\mathrm{E}}$ pathway (Scheme 14). ${ }^{17}$ 


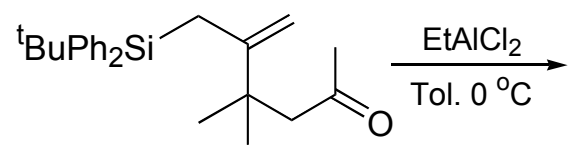

23

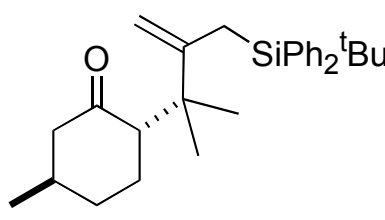

$24(+)$<smiles>C=C1CC(C)(O)CC1(C)C</smiles>

$25(67 \%)$

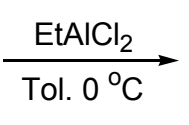<smiles>C=C1CC2(O)CC(C)CCC2C1(C)C</smiles>

$26(-)(70 \%)$

\section{Scheme 14}

Homologation $(\mathrm{C} \rightarrow \mathrm{C}+1)$ of the previous oxo-allylsilanes, followed by Lewis acidcatalyzed cyclization, allows the preparation of silicon-containing cyclohexenols. ${ }^{19}$ Effectively, epoxyallylsilanes 27 bearing the $t$-butyldiphenylsilyl group (prepared from the corresponding oxoallylsilane via sulfur ylides) undergo an uncommon tandem rearrangement-cyclization process, ${ }^{20}$ upon treatment with Lewis acids, where the first stage involves Lewis acid induced isomerization of the epoxy group to an aldehyde $\mathbf{2 8}$ and the second stage occurs by intramolecular carbonyl-ene reaction between the oxo group and the allylsilane unit (Scheme 15). This sequential type of process "epoxide rearrangement-carbonyl ene reaction" has no precedent in the chemical literature.

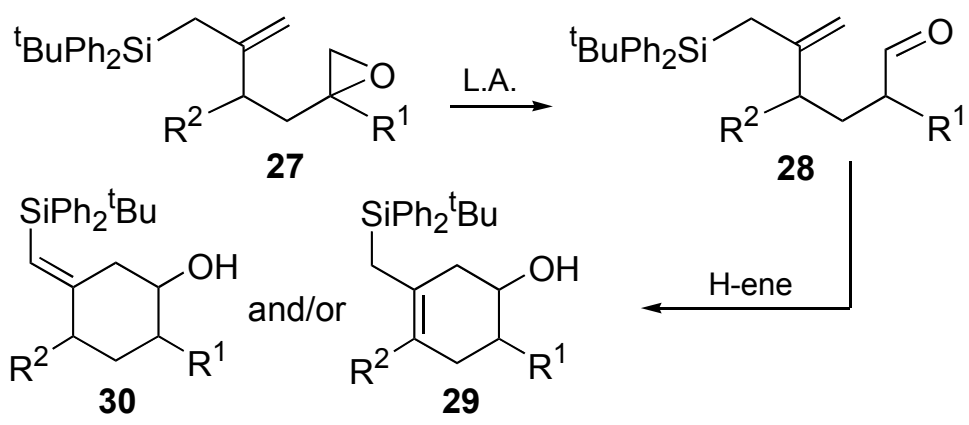

\section{Scheme 15}

Two pathways for the carbonyl ene reaction are observed: one leading to allylsilane containing cyclohexanols $\mathbf{2 9}$ when the epoxyallylsilane is nonsubstituted, 2-, or 4monosubstituted and other leading to vinylsilane containing cyclohexanols $\mathbf{3 0}$ when the epoxyallylsilane is 2,4-disubstituted or trisubstituted (scheme 16). ${ }^{19}$ 

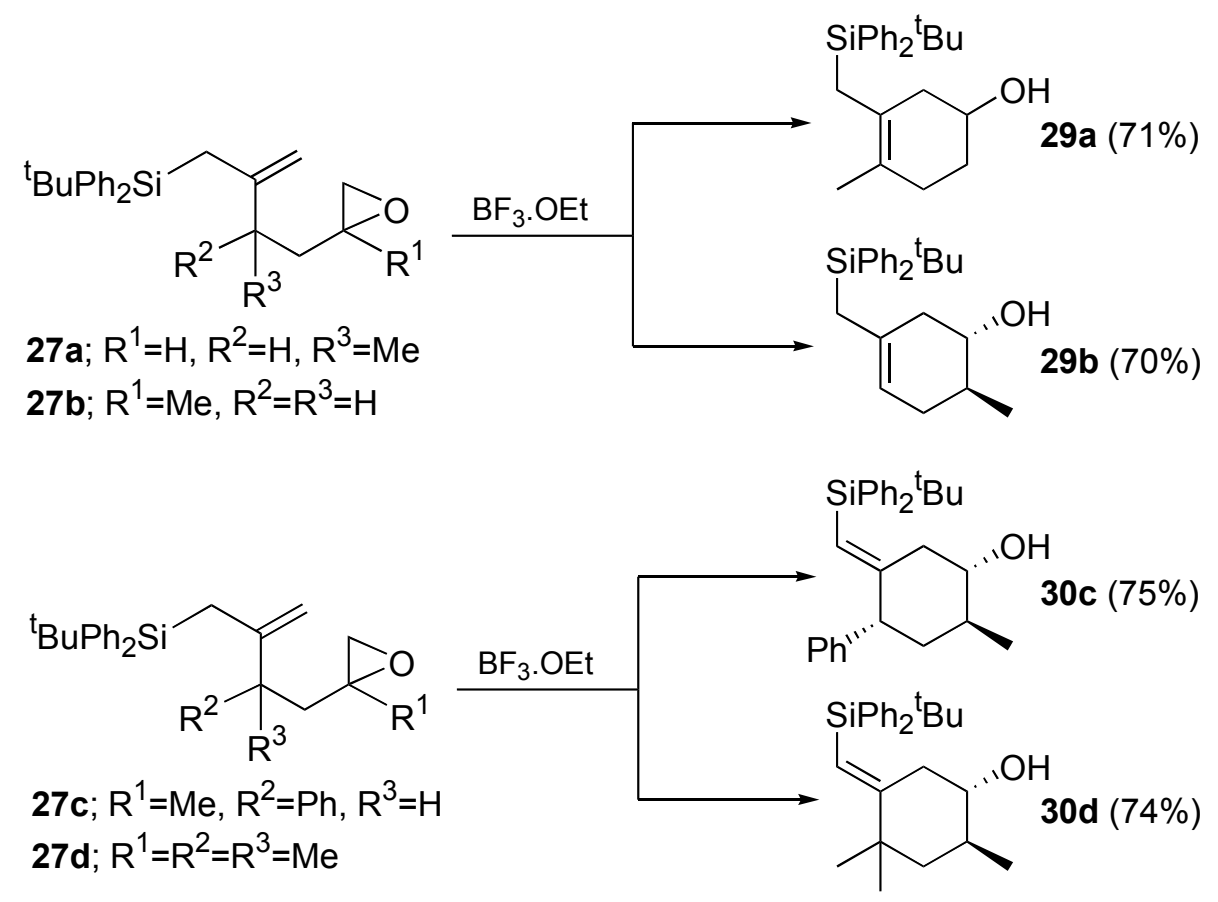

\section{Scheme 16}

Three transition states $\mathbf{A}, \mathbf{B}$ and $\mathbf{C}$ have been proposed to explain the observed results (scheme 17). They may account for all the isolated products. In the case of 2-, or 4monosubstituted epoxyallylsilanes, the molecular structure of the intermediate aldehyde shows a well-positioned endocyclic axial hydrogen which favors completion of the $\mathrm{H}$-ene reaction, where substituents in C-2 or C-4 are occupying equatorial positions, as it is shown in the chair-like transition state $\mathbf{A}\left(\mathrm{R}^{1}\right.$ or $\left.\mathrm{R}^{2}=\mathrm{H}\right)$. This model is energetically very favored since the endocyclic axial $\mathrm{C}-\mathrm{H}$ bond and the sigma $\mathrm{C}$-Si bond are both coplanar to the empty carbon p-orbital, and therefore $\mathrm{C}-\mathrm{Si}$ hyperconjugation is not perturbed. Formation of alcohols trans as the major products is a consequence of the difference of energy between $\mathbf{A}$ and $\mathbf{B}$, the latter being more crowded. $^{19}$
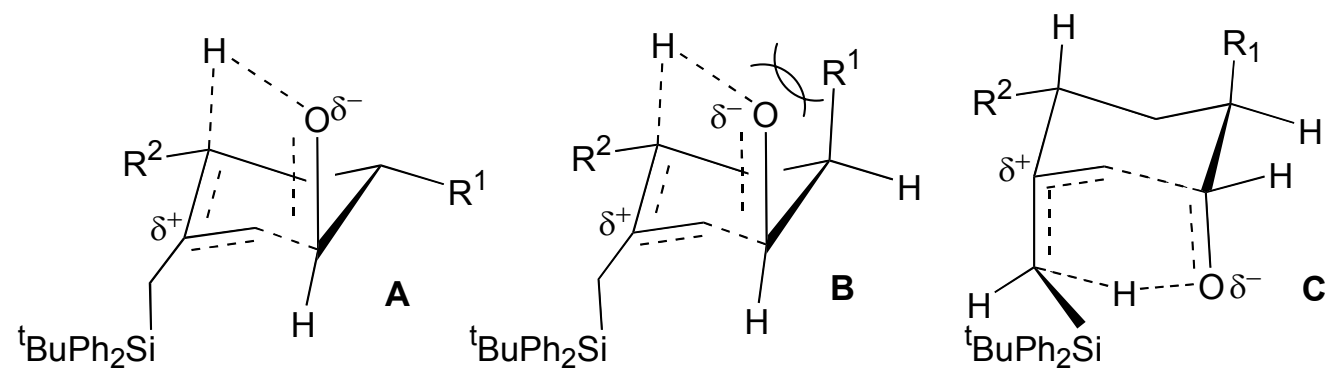

\section{Scheme 17}


In the case of 2,4-disubstituted epoxyallylsilanes $\left(\mathrm{R}^{1}\right.$ and $\left.\mathrm{R}^{2} \neq \mathrm{H}\right)$, the pathway for the ene reaction depends on the stereochemistry of the intermediate aldehyde $\mathbf{2 8}$. Thus, for the stereoisomer with both substituents $\mathrm{C}-2$ and C-4 in equatorial positions, the transition state $\mathbf{A}$ is still the most favored one, since there is an appropriate pseudoaxial hydrogen in the allylic position. However, the stereoisomer with one substituent equatorial and the other axial (transition states $\mathbf{B}$ or $\mathbf{C}$ ) might have serious difficulties to follow model $\mathbf{B}$ due to steric hindrance. In this case, the ene reaction is still possible with the allylic hydrogens alpha to silicon, as it is shown in transition state $\mathbf{C}$. In the model $\mathbf{C}, \mathrm{C}$-Si hyperconjugation is somewhat perturbed since coplanarity is partially lost, but at least, unfavorable sterical interactions are avoided. The latter transition state $\mathbf{C}$ is the only possible in case of epoxyallylsilanes disubstituted at C-4 as $\mathbf{2 7 d}$ (scheme 16). It should be noted that transition states $\mathbf{A}$ or $\mathbf{B}$ lead to allylsilane containing cyclohexanols $\mathbf{2 9}$ with an endocyclic double bond, whereas transition state $\mathbf{C}$ leads to vinylsilane containing cyclohexanols $\mathbf{3 0}$ with an exocyclic double bond. ${ }^{19}$

In summary, in this account we show that the carbonyl-ene reaction, in allylsilane chemistry, is a powerful tool and a useful strategy for ring formation, especially the intramolecular version, where $\mathrm{C}-\mathrm{C}$ bond formation occurs through a highly stereocontrolled silicon assisted process of much interest and wide application in Organic Synthesis.

\section{Experimental Section}

Silylcupration of allene. General procedure. A solution of phenyldimethylsilyl-lithium (3 $\mathrm{mmol})$, prepared in THF $(3 \mathrm{ml})$ from phenyldimethylchlorosilane and lithium shots $\left(0{ }^{\circ} \mathrm{C}\right.$ to r.t. overnight), was added by syringe to a stirred suspension of copper(I) cyanide (269 mg, $3 \mathrm{mmol}$ ) in THF $(5 \mathrm{ml})$ at $0{ }^{\circ} \mathrm{C}$, under argon atmosphere. The resulting black mixture was stirred at this temperature for $30 \mathrm{~min}$, and then used immediately. The solution of the phenyldimethylsilylcyanocuprate $1(3 \mathrm{mmol})$ in THF $(8 \mathrm{ml})$ was cooled at $-40{ }^{\circ} \mathrm{C}$ and a slight excess of allene was added from a balloon (1,2-propadiene was supplied by Air Liquide S. A. in lecture bottles). The mixture was stirred for $1 \mathrm{~h}$ at this temperature and the reagent $\mathbf{2}$ is ready to use. $t$-Butyldiphenylsilylcyanocuprates were prepared in the same manner. The intermediate cuprates resulting from addition to allene are stable enough in solution to be used without special precautions other than dry atmosphere, however long periods of times before using the reagent are not recommended.

Reaction of the intermediate cuprates with enones. General procedure. $\mathrm{BF}_{3} \cdot \mathrm{Et}_{2} \mathrm{O}(0.38 \mathrm{ml}, 3$ mmol) was added at $-78{ }^{\circ} \mathrm{C}$ to a stirred solution of the intermediate cuprate $(3 \mathrm{mmol})$ and the mixture stirred for $10 \mathrm{~min}$ at this temperature, then $3.5 \mathrm{mmol}$ of the $\alpha, \beta$-unsaturated oxocompound in THF $(5 \mathrm{ml})$ were added dropwise at $-40{ }^{\circ} \mathrm{C}$ and the resulting mixture was kept at this temperature for $1 \mathrm{~h}$. After gentle warming to $0{ }^{\circ} \mathrm{C}$ (over $0.5 \mathrm{~h}$ ) the mixture was quenched with aq sat. $\mathrm{NH}_{4} \mathrm{Cl}$ solution and extracted with $\mathrm{Et}_{2} \mathrm{O}$. The organic phase was dried, evaporated and chromatographed (EtOAc:hexanes) to give the corresponding oxoallylsilanes. 
6-t-Butyldiphenylsilylmethyl-5-methyl-6-hepten-3-one (16). Colorless oil, (89\%); IR (neat): 1700, 1620, $1100 \mathrm{~cm}^{-1}$; ${ }^{1} \mathrm{H}$ NMR $\left(\mathrm{CDCl}_{3}, 300 \mathrm{MHz}, \delta\right): 7.68-7.33(10 \mathrm{H}, \mathrm{m}), 4.61(1 \mathrm{H}, \mathrm{s}), 4.60$ $(1 \mathrm{H}, \mathrm{s}), 2.30-2.13(5 \mathrm{H}, \mathrm{m}), 2.20(2 \mathrm{H}, \mathrm{s}), 1.07(9 \mathrm{H}, \mathrm{s}), 0.96(3 \mathrm{H}, \mathrm{t}, J=7.2), 0.80(3 \mathrm{H}, \mathrm{d}, J=6.5)$; ${ }^{13} \mathrm{C} \mathrm{NMR}\left(\mathrm{CDCl}_{3}, 75 \mathrm{MHz}, \delta\right): 210.6,150.6,136.3,134.5,129.1,127.4,108.9,48.6,36.6,35.8$, 27.8, 19.4, 18.7, 18.5, 7.7. MS(EI) m/z: $321\left(\mathrm{M}^{+}{ }^{\mathrm{t}} \mathrm{Bu}, 19 \%\right), 243,199$ (100). Anal. Calcd. for $\mathrm{C}_{25} \mathrm{H}_{34} \mathrm{OSi}$ : C, 79.31; H, 9.05. Found: C, 79.50; H, 9.20.

Cyclization of oxoallylsilanes. General Procedure. Typically, $\mathrm{EtAlCl}_{2}\left(2.4 \mathrm{mmol}_{1} 1.8 \mathrm{M}\right.$ in toluene) was added slowly to a solution of the oxoallylsilane $(2 \mathrm{mmol})$ in toluene $(8 \mathrm{ml})$ at $0{ }^{\circ} \mathrm{C}$, under argon. After stirring for $1 \mathrm{~h}$ at $0{ }^{\circ} \mathrm{C}$, brine was added $(5 \mathrm{~mL})$ and the mixture extracted with $\mathrm{Et}_{2} \mathrm{O}$, dried and evaporated. Purification by flash-chromatography (EtOAc:hexanes) gave the corresponding cyclopentenols.

1-Ethyl-4-methyl-3-t-butyldiphenylsilylmethyl-3-cyclopenten-1-ol (21). Colorless oil, (85\%); IR (neat): $3400,1100 \mathrm{~cm}^{-1} ;{ }^{1} \mathrm{H}$ NMR $\left(300 \mathrm{MHz}, \mathrm{CDCl}_{3}, \delta\right): 7.65-7.34(\mathrm{~m}, 10 \mathrm{H}), 2.24(\mathrm{~d}, J=$ $16.5,1 \mathrm{H}), 2.17(\mathrm{~s}, 2 \mathrm{H}), 2.06(\mathrm{~d}, J=16.5,1 \mathrm{H}), 2.03(\mathrm{~d}, J=16.5,1 \mathrm{H}), 1.85(\mathrm{~d}, J=16.5,1 \mathrm{H}), 1.47$ $(\mathrm{s}, 3 \mathrm{H}), 1.38(\mathrm{q}, J=7.2,2 \mathrm{H}), 1.20(\mathrm{~s}, 1 \mathrm{H}), 1.10(\mathrm{~s}, 9 \mathrm{H}), 0.76(\mathrm{t}, J=7.2,3 \mathrm{H}) ;{ }^{13} \mathrm{C} \mathrm{NMR}(75 \mathrm{MHz}$, $\left.\mathrm{CDCl}_{3}, \delta\right)$ : 136.0, 134.8, 134.6, 129.6, 129.1, 127.4, 127.3, 79.4, 51.9, 51.4, 33.0, 27.6, 18.3, 14.2, 12.2, 8.7; MS(EI) m/z: 378 (M, 5\%), 321, 239, 199 (100); Anal. Calcd. for $\mathrm{C}_{25} \mathrm{H}_{34} \mathrm{OSi}$ : C, 79.31; H, 9.05. Found: C, 79.61; H, 9.24.

Synthesis of epoxyallylsilanes. General procedure. To a solution of trimethylsulphonium iodide $(1 \mathrm{mmol})$ in dry THF $(5 \mathrm{ml})$ was added dropwise n-BuLi (1 mmol, 1.6 M BuLi in hexanes) and the mixture stirred for $5 \mathrm{~min}$ at $0^{\circ} \mathrm{C}$. Then a solution of the oxoallylsilane $(0.8 \mathrm{mmol})$ in $\mathrm{THF}$ $(1 \mathrm{ml})$ is added. After stirring for an additional $30 \mathrm{~min}$ at $0^{\circ} \mathrm{C}$ and $1 \mathrm{~h}$ at r.t. brine $(10 \mathrm{ml})$ is added and the mixture extracted with ether, dried and evaporated to dryness. The residue was purified by chromatography to give the corresponding epoxyallylsilanes . Compound 27c was isolated as a mixture $(\sim 1: 1)$ of diastereomers, which could be cleanly separated by chromatography.

5-t-Butyldiphenylsilylmethyl-2,4,4-trimethyl-1,2-epoxyhex-5-ene (27d). Colorless oil, (78\%); ${ }^{1} \mathrm{H}$ NMR (300 MHz, $\left.\mathrm{CDCl}_{3}, \delta\right): 7.73-7.27$ (m, 10H), 4.79 (s, 1H), $4.67(\mathrm{~s}, 1 \mathrm{H}), 2.63$ (d, J= 4.9 $\mathrm{Hz}, 1 \mathrm{H}), 2.54(\mathrm{dd}, J=4.9$ and $1.1 \mathrm{~Hz}, 1 \mathrm{H}), 2.16(\mathrm{~s}, 2 \mathrm{H}), 2.07(\mathrm{dd}, J=14.3$ and $1.1 \mathrm{~Hz}, 1 \mathrm{H}), 1.45$ $(\mathrm{d}, J=14.3 \mathrm{~Hz}, 1 \mathrm{H}), 1.33\left(\mathrm{~s}, 9 \mathrm{H},{ }^{\mathrm{t}} \mathrm{Bu}-\mathrm{Si}\right), 1.06(\mathrm{~s}, 3 \mathrm{H}), 1.03(\mathrm{~s}, 3 \mathrm{H}), 1.01(\mathrm{~s}, 3 \mathrm{H}) ;{ }^{13} \mathrm{C}$ NMR $(75$

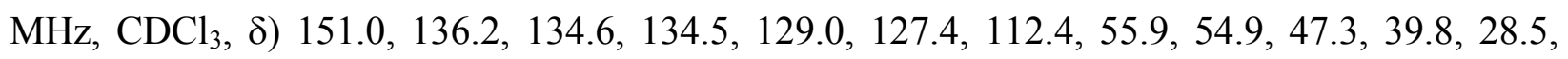
27.9, 27.5, 22.2, 18.5, 12.8; Anal. Calcd for $\mathrm{C}_{26} \mathrm{H}_{36} \mathrm{SiO}$ : C, 79.53; H, 9.24. Found: C, 79.85; H, 9.58 .

Cyclization of epoxyallylsilanes. General procedure. $\mathrm{BF}_{3} . \mathrm{OEt}_{2}(1.4 \mathrm{mmol})$ was slowly added to a solution of the epoxyallylsilane $(1 \mathrm{mmol})$ in DCM $(10 \mathrm{ml})$ under nitrogen at $0^{\circ} \mathrm{C}$. After stirring for $30 \mathrm{~min}$ at this temperature brine was added and the mixture extracted with ether. The organic layer was dried over $\mathrm{MgSO}_{4}$, the solvent was evaporated and the residue purified by chromatography to give the corresponding cyclohexanols.

3-t-Butyldiphenylsilylmethyl-4-methylcyclohex-3-enol (29a). Colorless oil, (71\%); ${ }^{1} \mathrm{H}$ NMR $\left(300 \mathrm{MHz}, \mathrm{CDCl}_{3}, \delta\right): 7.65-7.55(\mathrm{~m}, 4 \mathrm{H}), 7.45-7.30(\mathrm{~m}, 6 \mathrm{H}), 3.69-3.61(\mathrm{~m}, 1 \mathrm{H}), 2.16(\mathrm{~d}, J=$ $15.0 \mathrm{~Hz}, 1 \mathrm{H}), 2.08(\mathrm{~d}, J=15.0 \mathrm{~Hz}, 1 \mathrm{H}), 2.06-1.99(\mathrm{~m}, 1 \mathrm{H}), 1.85-1.63(\mathrm{~m}, 5 \mathrm{H}), 1.53-1.44(\mathrm{~m}$, 
1H), $1.33(\mathrm{~s}, 3 \mathrm{H}), 1.09$ (s, 9H); ${ }^{13} \mathrm{C} \mathrm{NMR}\left(75 \mathrm{MHz}, \mathrm{CDCl}_{3}, \delta\right): 136.2,134.9,134.8,129.0,127.2$, 126.6, 121.2, 66.9, 40.5, 31.0, 29.9, 27.6, 19.8, 18.3, 16.6. Anal. Calcd for $\mathrm{C}_{24} \mathrm{H}_{32} \mathrm{OSi}$ : C, 79.06; H, 8.85. Found: C, 79.41; H, 9.11.

(E)-[1 $\left.R^{*}, 2 R^{*}, 4 S^{*}\right]-5-t$-Butyldiphenylsilylmethylene-2-methyl-4-phenylcyclohexanol (30c). Colorless oil, (75\%); IR (neat): 3560, 3450, 1610, 1430, $1100 \mathrm{~cm}^{-1} ;{ }^{1} \mathrm{H} \mathrm{NMR}\left(300 \mathrm{MHz}, \mathrm{CDCl}_{3}\right.$,

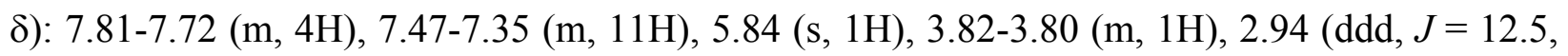
9.1 and $4.1 \mathrm{~Hz}, 1 \mathrm{H}), 2.44(\mathrm{dd}, J=10.1$ and $4.5 \mathrm{~Hz}, 1 \mathrm{H}), 2.22(\mathrm{dd}, J=13.2$ and $4.1 \mathrm{~Hz}, 1 \mathrm{H}), 1.80$ $(\mathrm{dd}, J=13.2$ and $9.1 \mathrm{~Hz}, 1 \mathrm{H}), 1.68-1.57(\mathrm{~m}, 2 \mathrm{H}), 1.04(\mathrm{~s}, 9 \mathrm{H}), 0.99(\mathrm{~d}, J=6.5 \mathrm{~Hz}, 3 \mathrm{H}) ;{ }^{13} \mathrm{C}$ NMR (75 MHz, $\left.\mathrm{CDCl}_{3}, \delta\right): 161.5,142.1,136.0,135.3,129.1,128.4,127.7,127.6,127.5,126.0$, 120.2, 75.6, 50.6, 40.5, 35.8, 34.1, 27.3, 18.2, 17.9; $\mathrm{MS}(\mathrm{EI}) \mathrm{m} / z: 441\left(\mathrm{M}^{+}\right), 423\left(\mathrm{M}^{+}-\mathrm{H}_{2} \mathrm{O}\right), 239$ $\left(\mathrm{Ph}_{2}{ }^{\mathrm{t}} \mathrm{BuSi}\right), 199$; Anal. Calcd for $\mathrm{C}_{30} \mathrm{H}_{36} \mathrm{OSi}$ : C, 81.76; H, 8.23. Found: C, 82.07; H, 8.57.

\section{Acknowledgements}

This work was financially supported by the "Junta de Castilla y León" (project VA050/2004) and the Spanish "Ministerio de Ciencia y Tecnología”(project BQU2003-03035).

\section{References and Notes}

1. (a) Fleming, I. In Comprehensive Organic Synthesis; Trost, B. M.; Fleming, I., Eds.; Pergamon: Oxford, 1991; Vol 2. (b) Fleming, I. Science of Synthesis: Houben-Weyl Methods of Molecular Transformations; Thieme: Stuttgart, 2001; Vol. 4.

2. Barbero, A.; Pulido, F. J. Acc. Chem. Res. 2004, 37, 817.

3. (a) Fleming, I.; Pulido, F. J. Chem. Commun. 1986, 1010. (b) Fleming, I.; Pulido, F. J.; Rowley, M.; Cuadrado, P.; González, A. M. Tetrahedron (Symposia-in-Print) 1989, 45, 413. (c) Krause, N. Modern Organocopper Chemistry; Wiley-VCH: Dortmund, Germany, 2002, Chap. 3.

4. Barbero, A.; García, C.; Pulido, F. J. Tetrahedron (Symposia-in-Print) 2000, 56, 2739.

5. (a) Monti, H.; Audran, G.; Féraud, M.; Monti, J. P.; Leandri, G. Tetrahedron 1996, 52, 6685. (b) Monti, H.; Audran, G.; Monti, J.-P.; Leandri, G. J. Org. Chem. 1996, 61, 6061.

6. Apart from our work in the area (ref. 17 and 19) little work has been reported on the intramolecular version of the carbonyl-ene reaction of allylsilanes. An example of this reaction has been published by Monti and co-workers: Eur. J. Org. Chem. 1999, 8, 1825 (ref.12).

7. (a) Mikami, K.; Shimizu, M. Chem Rev. 1992, 92, 1021. (b) Dubac, J.; Laporterie, A. Chem. Rev. 1987, 87, 319.

8. Loncharich, R. J.; Houk, K. N. J. Am. Chem. Soc. 1987, 109, 6947.

9. Mikami, K.; Loh, T.-P.; Nakai, T. Tetrahedron Lett. 1988, 29, 6305. 
10. Mikami, K.; Wakabayashi, H.; Nakai, T. J. Org. Chem. 1991, 56, 4337. For a general discussion on mechanistic aspects, see also ref. $7 \mathrm{a}$.

11. O’Brien, M.; Nicholas, H.; Thomas, E. J. Tetrahedron Lett. 2002, 43, 5491.

12. Monti, H.; Laval, G.; Féraud, M. Eur. J. Org. Chem. 1999, 8, 1825.

13. (a) Dumeunier, R.; Leclercq, C.; Markó, I. E. Tetrahedron Lett. 2002, 43, 2307. (b) Leroy, B.; Dumeunier, R.; Markó, I. E. Tetrahedron Lett. 2000, 41, 10215. (c) Markó, I. E.; Bayston, D. J. Tetrahedron Lett. 1993, 34, 6595.

14. D’Aniello, F.; Mann, A.; Mattii, D.; Taddei, M. J. Org. Chem. 1994, 59, 3762.

15. Robertson, J.; O'Connor, G. Tetrahedron Lett. 1996, 37, 3411.

16. (a) Blanco, F. J.; Cuadrado, P.; Fleming, I.; González, A. M.; Pulido, F. J. Tetrahedron Lett. 1994, 35, 8881. (b) Barbero, A.; García, C.; Pulido, F. J. Tetrahedron Lett. 1999, 40, 6649.

17. Barbero, A.; Castreño, P.; García, C.; Pulido, F. J. J.Org. Chem. 2001, 66, 7723.

18. Cai, J.; Davies, A. G. J. Chem. Soc., Perkin Trans. 2 1992, 1743. See also: Hoffmann, H. M. R. Angew. Chem. Int. Ed. 1969, 8, 556.

19. Barbero, A.; Castreño, P.; Fernández, G.; Pulido, F. J. J.Org. Chem. 2005, 70, 10747.

20. Barbero, A.; Castreño, P.; Pulido, F. J. Org. Lett. 2003, 5, 4045. See also: Barbero, A.; Castreño, P.; Pulido, F. J. J. Am. Chem. Soc. 2005, 127, 8022. 